九州大学学術情報リポジトリ

Kyushu University Institutional Repository

\title{
High-pressure torsion of TiFe intermetallics for activation of hydrogen storage at room temperature with heterogeneous nanostructure
}

\section{Edalati, Kaveh}

Department of Materials Science and Engineering, Faculty of Engineering, Kyushu University | WPI International Institute for Carbon-Neutral Energy Research (WPI-I2CNER), Kyushu University

Matsuda, Junko

Department of Mechanical Engineering, Faculty of Engineering, Kyushu University | WPI

International Institute for Carbon-Neutral Energy Research (WPI-I2CNER), Kyushu University

\section{Iwaoka, Hideaki}

Department of Materials Science and Engineering, Faculty of Engineering, Kyushu University I WPI International Institute for Carbon-Neutral Energy Research (WPI-I2CNER), Kyushu University

Toh, Shoichi

Research Laboratory for High Voltage Electron Microscopy, Kyushu University

他

http://hdl. handle. net/2324/26375

出版情報: International Journal of Hydrogen Energy. 38 (11)，pp.4622-4627，2013-04-15.

Elsevier

バージョン :

権利関係 : (C) 2013 Hydrogen Energy Publications, LLC. 


\title{
High-pressure torsion of TiFe intermetallics for activation of hydrogen storage at room temperature with heterogeneous nanostructure
}

\author{
Kaveh Edalati $^{\text {a,b,*}, ~ J u n k o ~ M a t s u d a ~}{ }^{\text {b,c }}$, Hideaki Iwaoka ${ }^{\text {a,b }}$, Shoichi Toh ${ }^{\text {d }}$, \\ Etsuo Akiba ${ }^{\text {b,c }}$, Zenji Horita ${ }^{\text {a,b }}$
}

a Department of Materials Science and Engineering, Faculty of Engineering, Kyushu University, Fukuoka 819-0395, Japan

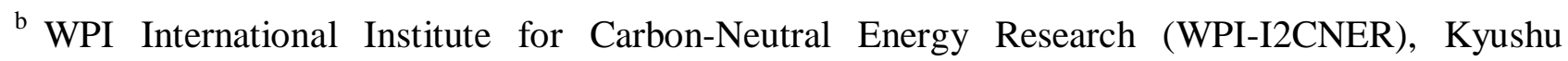
University, Fukuoka 819-0395, Japan

c Department of Mechanical Engineering, Faculty of Engineering, Kyushu University, Fukuoka 819-0395, Japan

d Research Laboratory for High Voltage Electron Microscopy, Kyushu University, Fukuoka 819-0395, Japan

\begin{abstract}
TiFe is a potential candidate for the stationary hydrogen storage systems, but it requires initial activation to absorb hydrogen. This study shows that TiFe processed by highpressure torsion (HPT) absorbs and desorbs 1.7 wt.\% hydrogen at room temperature without activation. The absorption pressure decreases from $2 \mathrm{MPa}$ in the first hydrogenation cycle to $0.7 \mathrm{MPa}$ in the latter cycles. The HPT-processed TiFe exhibits heterogeneous microstructures composed of nanograins, coarse-grains, amorphous-like phases and disordered phases with a high hardness of $\sim 1050 \mathrm{Hv}$.
\end{abstract}

Keywords: Hydrogen storage; Severe plastic deformation (SPD); Hydride; Disordering; FeTi intermetallics; Ultrafine-grained.

*Corresponding author. Department of Materials Science and Engineering, Faculty of Engineering, Kyushu University, 744 Motooka, Nishi-ku, Fukuoka-shi, Fukuoka 819-0395, Japan.

Tel./fax: +8192802 2992

E-mail addresses: Kaveh.edalati@zaiko6.zaiko.kyushu-u.ac.jp, kavedalati@gmail.com (K. Edalati). 


\section{Introduction}

Iron-titanium intermetallic with B2-type crystal structure, TiFe, is a potential candidate for stationary hydrogen storage applications because of its low price, high storage capacity per unit volume, low hydrogenation temperatures and reversible hydriding dehydriding features [1-3]. A main drawback of the TiFe is the surface oxidation and thus the difficulty in hydrogenation [1-7]. The material usually requires exposure to $\mathrm{H}_{2}$ atmosphere under high pressures as several Mega-Pascals at elevated temperatures as $673 \mathrm{~K}$ for the activation before hydrogenation. Although there are several approaches for easier activation such as setting compositions to Ti-rich from the stoichiometric value [8], addition of $\mathrm{Mn}$ [9], $\mathrm{Ni}$ [10] and $\mathrm{Pd}$ [2], addition of $\mathrm{O}_{2}$ to the $\mathrm{H}_{2}$ atmosphere [11], and nanostructuring by ball milling [12,13], the material usually needs the activation process before hydrogenation.

Processing using severe plastic deformation (SPD) [14,15] may be a solution to activate the TiFe for hydrogenation. The influence of SPD on hydrogen storage in several materials was studied and improvement on the hydrogenation kinetic [16-27] and formation of strain-induced hydrides [28] have been reported. Among different SPD methods which are mainly used to achieve ultrafine grains [29-34], high-pressure torsion (HPT) provides an opportunity for processing hard and brittle intermetallics such as $\mathrm{Ni}_{3} \mathrm{Al}$ [35], TiNi [36], $\mathrm{Zr}_{3} \mathrm{Al}$ [37], $\mathrm{Cu}_{3} \mathrm{Au}$ [38], FeAl [38], $\mathrm{AlNi}$ [39] and $\mathrm{TiAl}$ [40]. In the HPT method, a disc is placed between two anvils under high pressure and shear strain, ( $\gamma=2 \pi r N / h, r$ : distance from disc center, $N$ : number of turns, $h$ : disc thickness), is introduced by rotating the anvils with respect to each other [41].

In this study, and for the first time, TiFe is severely deformed by HPT and hydrogen storage performance is demonstrated without activation before hydrogenation.

\section{Experimental materials and methods}

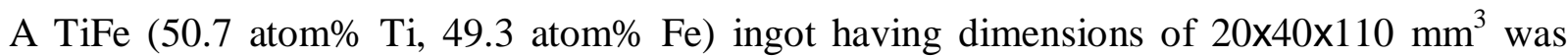
purchased from Japan Metals \& Chemicals Co., Ltd. in Tokyo after casting in an argon atmosphere but without processing for activation. Discs with $10 \mathrm{~mm}$ diameter and $0.8 \mathrm{~mm}$ thickness were cut from the ingot, annealed for $24 \mathrm{~h}$ at $1273 \mathrm{~K}$ under an argon atmosphere, and subjected to HPT processing at room temperature in the air under a pressure of $6 \mathrm{GPa}$ for $0.25-10$ turns with a rotation speed of $1 \mathrm{rpm}$. The HPT-processed discs were evaluated using Vickers microhardness, X-ray diffraction (XRD), optical microscopy (OM), transmission electron microscopy (TEM) and hydrogen storage analysis.

First, the discs were polished and the Vickers microhardness was measured with an applied load of $300 \mathrm{~g}$ for $15 \mathrm{~s}$ at $3.5 \mathrm{~mm}$ away from the disc center. Second, XRD analysis was performed using the $\mathrm{Cu} \mathrm{K} \alpha$ radiation with a scanning step of $0.01^{\circ}$ and a scanning speed of $0.5^{\circ} / \mathrm{min}$. Third, the polished discs were etched for $\mathrm{OM}$ in a solution of $2 \% \mathrm{HNO}_{3}, 2 \% \mathrm{HF}$ and $96 \% \mathrm{H}_{2} \mathrm{O}$. Fourth, thin foils for TEM were prepared from $3.5 \mathrm{~mm}$ away from the disc center with a focused ion beam system followed by ion milling. TEM was then performed at $300 \mathrm{kV}$ for microstructural observation including selected-area electron diffraction (SAED) analysis. Fifth, the hydrogen pressure-composition (P-C) isotherms were measured using three discs having a total weight of $\sim 1$ 
$\mathrm{g}$ in a Sieverts-type gas absorption apparatus at $303 \mathrm{~K}$. Since the samples were left in the air for long time after the annealing and after the HPT processing, they were evacuated by a rotary pump and kept at $423 \mathrm{~K}$ for $2 \mathrm{~h}$ before the measurements to remove the moisture.

\section{Results}

Fig. 1 shows P-C isotherms for (a) the annealed sample and (b) the HPT-processed sample after $N=10$. Note that the 4 th hydrogenation cycle in (b) was terminated after absorption. Several important points are derived from Fig. 1.
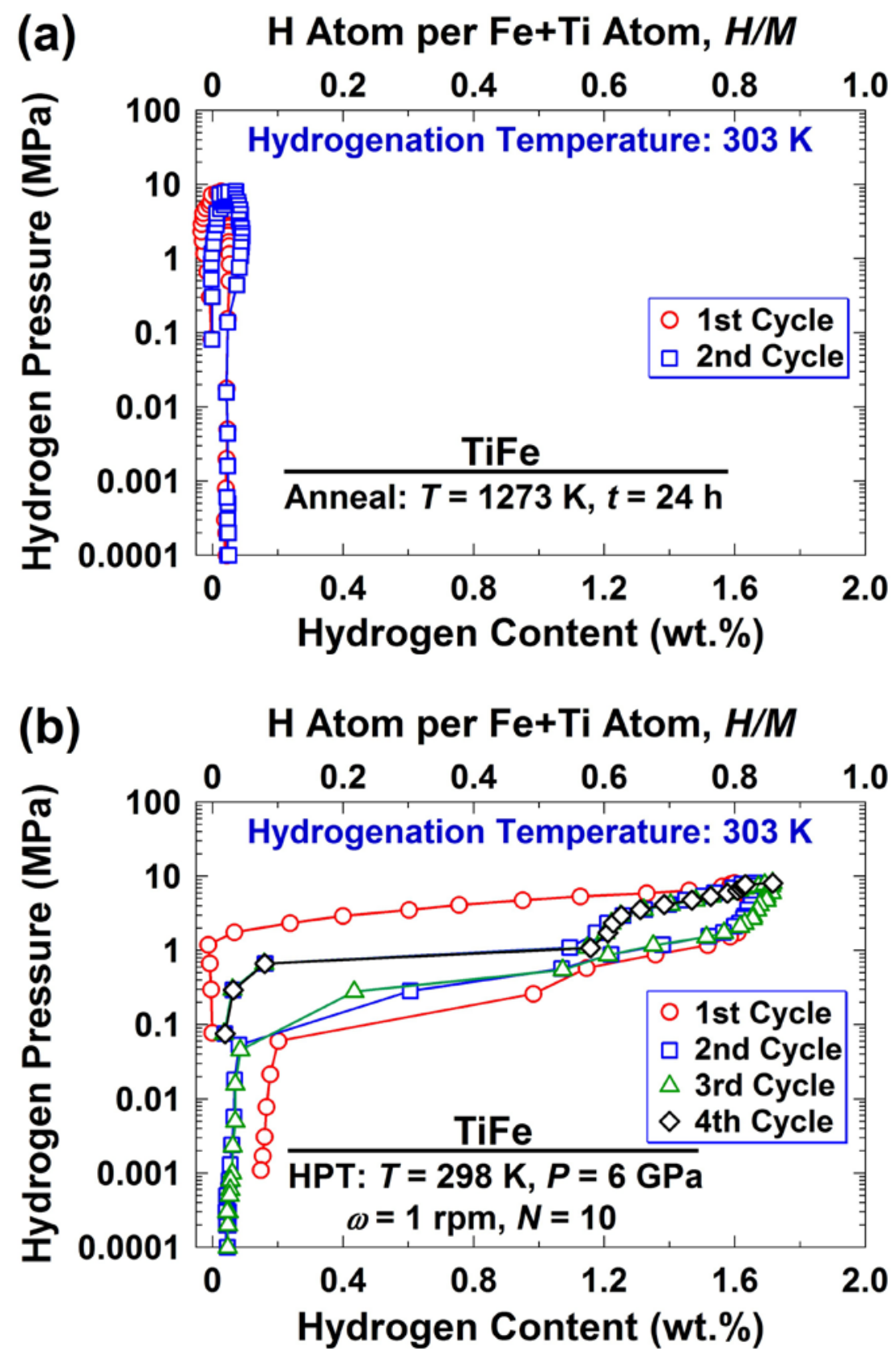

Fig. 1 P-C isotherms at $303 \mathrm{~K}$ for samples processed by (a) annealing at $1273 \mathrm{~K}$ for $24 \mathrm{~h}$ under argon and (b) HPT processing for 10 turns in air. 4th cycle in (b) was terminated after absorption for conducting XRD analysis. 
First, hydrogen absorption is negligible in the annealed sample, indicating that an activation process is necessary in consistency with Refs. [1-13]. Second, after HPT processing, the sample absorbsw1.7 wt.\% of hydrogen without any activation process, and this value is fairly close to the maximum capacity of hydrogen storage in TiFe (1.9 wt.\%) [1]. Third, for the HPT-processed sample, the absorption pressure decreases and the absorption/desorption hysteresis becomes smaller in the 2nd, 3rd and 4th cycles than the 1st cycle. It is most probable that this is due to generation of cracks and lattice defects during the 1st cycle as reported in Ref. [3]. Fourth, in the HPT-processed sample, the P-C isotherms after 1st cycle exhibit three distinct regions: (i) from 0.3 to $0.7 \mathrm{MPa}$, $H / M$ gradually increases to $\sim 0.1$, corresponding to solid solution of $\mathrm{H}$ in $\mathrm{TiFe}$ ( $\alpha$ phase), (ii) from 0.7 to $1 \mathrm{MPa}$ a plateau-like behavior appears with a significant increase of $H / M$ to $\sim 0.5$, corresponding to TiFeH formation ( $\beta$ phase), (iii) at higher pressures more than $1 \mathrm{MPa}$, a second plateau-like behavior appears with an increase of $H / \mathrm{M}$ to $\sim 0.9$, corresponding to $\mathrm{TiFeH}_{2}$ formation ( $\gamma$ phase) [1]. It is noted that the second plateau was not completed because of the pressure limitation (8 MPa) in the gas absorption apparatus, and this is the main reason that the complete hydrogen absorption of $1.9 \%$ could not be achieved in this study.

XRD patterns of the sample after annealing, after compression but without rotation $(N=0)$, after HPT for different numbers of turns and after hydrogen absorption (4th cycle in Fig. 1(b)) are shown in Fig. 2(a). Inspection of Fig. 2(a) indicates four important points. First, no visible peak is detected for Ti, Fe and $\mathrm{TiFe}_{2}$ after HPT. Second no visible peak is detected for $\mathrm{TiFeH}$ and $\mathrm{TiFeH}_{2}$ after HPT followed by hydrogen absorption. This interestingly indicates that the HPT-processed samples are not deactivated in the air, and thus, the hydrides decompose quickly under the ambient pressure, as known from Fig. 1(b), whereas the TiFe samples activated by heat treatment are deactivated quickly in the air [1]. Third, the peak intensity of (211) plane which was prominent in some annealed samples becomes very weak after HPT but instead the (110) peak intensity increases. This suggests that a texture develops such that the slip plane tends to be parallel to the disc surface by HPT. Fourth, the full width at half maximum (FWHM) of the (110) plane, as evaluated quantitatively in Fig. 2(b), increases with straining but saturates to a constant level at large strains. This peak broadening indicates the occurrence of lattice strain, formation of lattice defects and grain refinement, which all can contribute to improvement of the hydrogen storage performance [16-27].

The microhardness variations are shown in Fig. 3 with the shear strain for the samples after HPT processing including the hardness level for the annealed sample. The hardness increases with increasing shear strain at early stages of straining but saturates to a constant level. It should be noted that this hardness behavior is similar to the behavior of metals with high melting temperatures such as Hf [28]. The hardness level at the saturation is as high as $1050 \mathrm{Hv}$ and it is the highest reported in SPD-processed materials [14-41]. Measurements showed that the difference between the hardness on the disc surface and the hardness at the midpoint of thickness was $\sim 10 \%$. Similar differences across the disc thickness were also reported in several other materials [33,36,38]. Finally, it should be noted that the hardness values were measured using two different pairs of HPT anvils: one pair is made of a tool steel and the other pair of WC- $11 \%$ Co. As shown in Fig. 3, there is no significant difference in the hardness behavior between the two pairs of the anvils. 

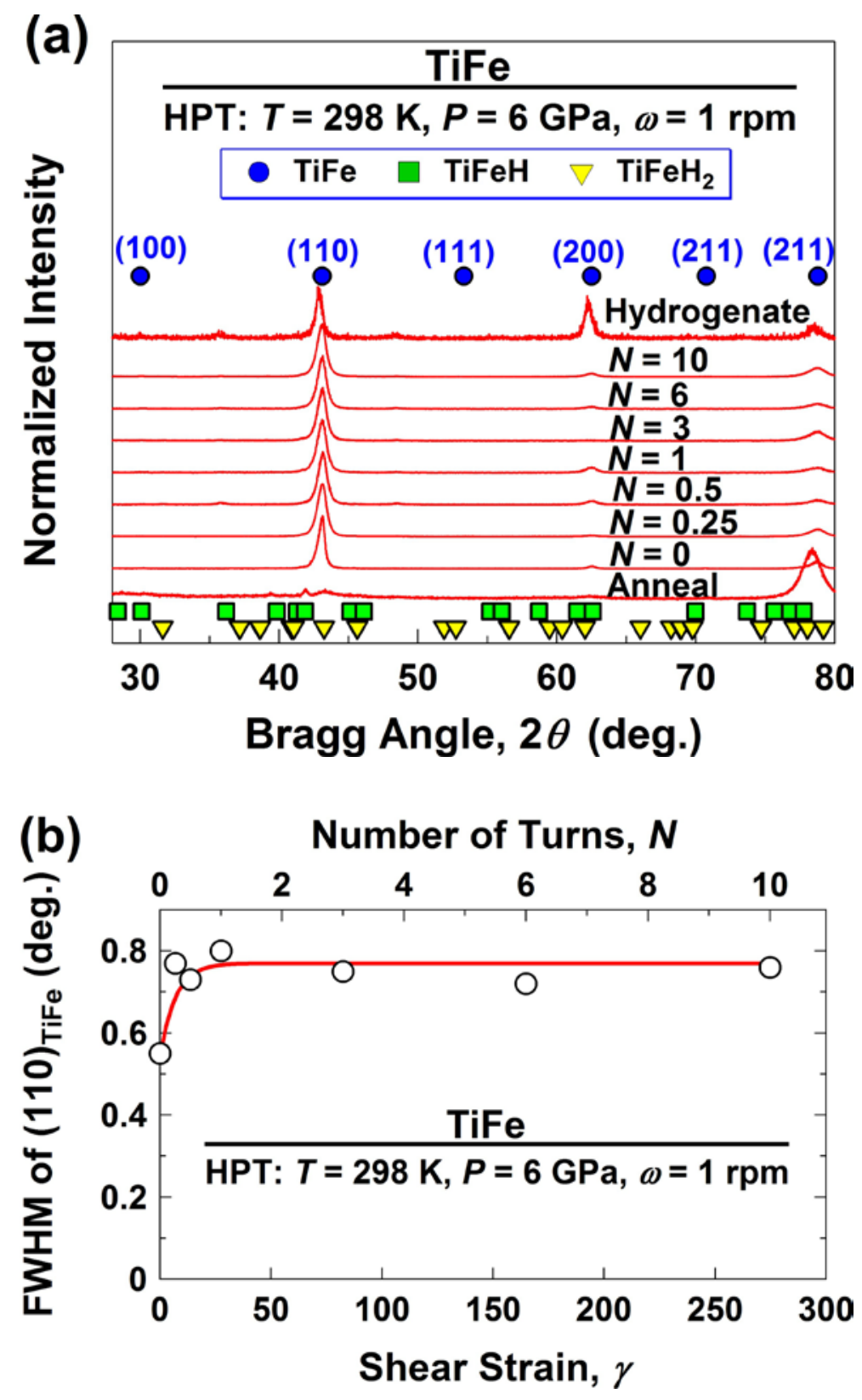

Fig. 2 (a) XRD profiles for samples processed for various turns including annealed sample and sample processed by HPT for 10 turns and subjected to hydrogen absorption. (b) FWHM for (110) peak of TiFe plotted against shear strain and number of turns.

Fig. 4 shows an OM micrograph of (a) the annealed sample and TEM micrographs including SAED patters after processing for (b-d) $N=0.25$ (early stages of straining) and (e-h) $N=10$ (saturated state). In Fig. 4, micrographs (c) and (d) are dark-field images of (b) and micrographs (f) and (g) are dark-field images of (e) taken from the upper surface of discs and (h) is a dark-field image taken from the mid-point of thickness. All dark-field images were taken with diffracted beams indicated by arrows in the SAED patterns. Observation shows several important points. First, the microstructure after annealing in (a) consists of large grains with an average grain size of $\sim 750$ $\mu \mathrm{m}$. Second, after $N=0.25$, a heterogeneous microstructure develops, which consists of coarse grains as in (c) and nanograins as in (d). Third, the microstructures after $N=10$ consist of coarse 
grains, as marked $\mathbf{A}$ in (e-g), and nanograins, as marked $\mathbf{B}$ in (e-g). It should be noted that the microstructures after $N=0.5$ and 10 were reasonably similar but, when compared with the microstructures after $N=0.25$, the nanograin size now becomes smaller. Fourth, the microstructure at the mid-point of thickness in (h) appears to be more homogenous than that at the disc surface shown in (e-g). Fifth, the ring-shape halo in the SAED patterns in (f-h) indicates the presence of amorphous-like or medium-range ordered phases at the saturated state. Sixth, the absence of superlattice diffraction corresponding to (100) plane in the SAED patterns in (f-h) indicates that disordering have also occurred during the HPT processing. Local disordering after HPT was also reported in several other intermetallics such as $\mathrm{TiNi}$ [36] and $\mathrm{Cu}_{3} \mathrm{Au}$ [38]. Finally, it should be noted that the heterogeneous evolution of microstructure after processing with HPT was reported in pure magnesium [20], pure titanium [42] and several other intermetallics [35-38], and the formations of nanograins and amorphous phase were reported in TiFe after processing by ball milling $[12,13]$.

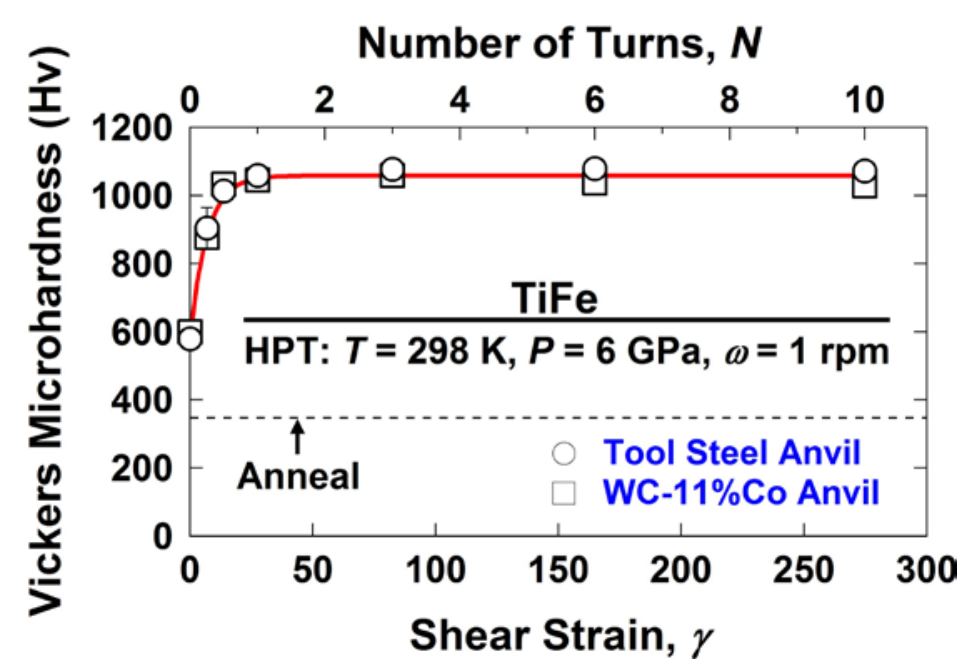

Fig. 3 Microhardness plotted against shear strain and number of turns for samples processed by HPT using tool steel and WC-11\% Co anvils.

\section{Discussion}

A question arises from the current investigation why TiFe absorbs hydrogen after HPT. Since an oxide layer forms on the surface of TiFe, it does not absorb hydrogen without an activation process. Different mechanisms were suggested for the activation of TiFe. One is due to the elemental segregation on the surface and the formation of active catalysts for hydrogen uptake such as Fe clusters [5,6,11], $\mathrm{TiO}_{2}$ [7] and $\mathrm{TiFe}_{2}$ [7]. Another one is due to dissolution of surface oxides and the formation of catalytically active $\mathrm{TiFeO}_{\mathrm{x}}$ [7]. However, the formation of such active catalysts seems to be inconsistent with the present study because neither of $\mathrm{Fe}, \mathrm{TiO}_{2}, \mathrm{TiFe}_{2}$ and $\mathrm{TiFeO}_{\mathrm{x}}$, could be detected in the HPT-processed samples within the sensitivity limits of XRD and SAED analyses. It is noted that the precise compositions of thin oxides and intermetallics on the surface and subsurface, which are under investigation in ongoing experiments, should be examined using surface analysis such as X-ray photoelectron spectroscopy (XPS). The other mechanism for the 
activation of TiFe may be due to an enhanced diffusion of hydrogen as the incubation timefor activation corresponded to the time required for the diffusion of hydrogen through the oxide layer [4]. This seems consistent with the fact that the diffusivity can strongly be enhanced by SPD processing [43,44] because of high concentration of vacancies [45], high dislocation density [29,30] and large fractions of grain boundaries [14,43]. Therefore, it is probable that the enhanced diffusivity can be a reason for the activation of TiFe after HPT processing. Furthermore, there may be two additional probable reasons for the activation arising from (i) a structural change of surface oxides due to the formation of nanograins through HPT processing [12], and (ii) partial amorphization and disordering occurred during HPT. The proper mechanism underlying the activation of TiFe after processing by HPT is under investigation in ongoing experiments.

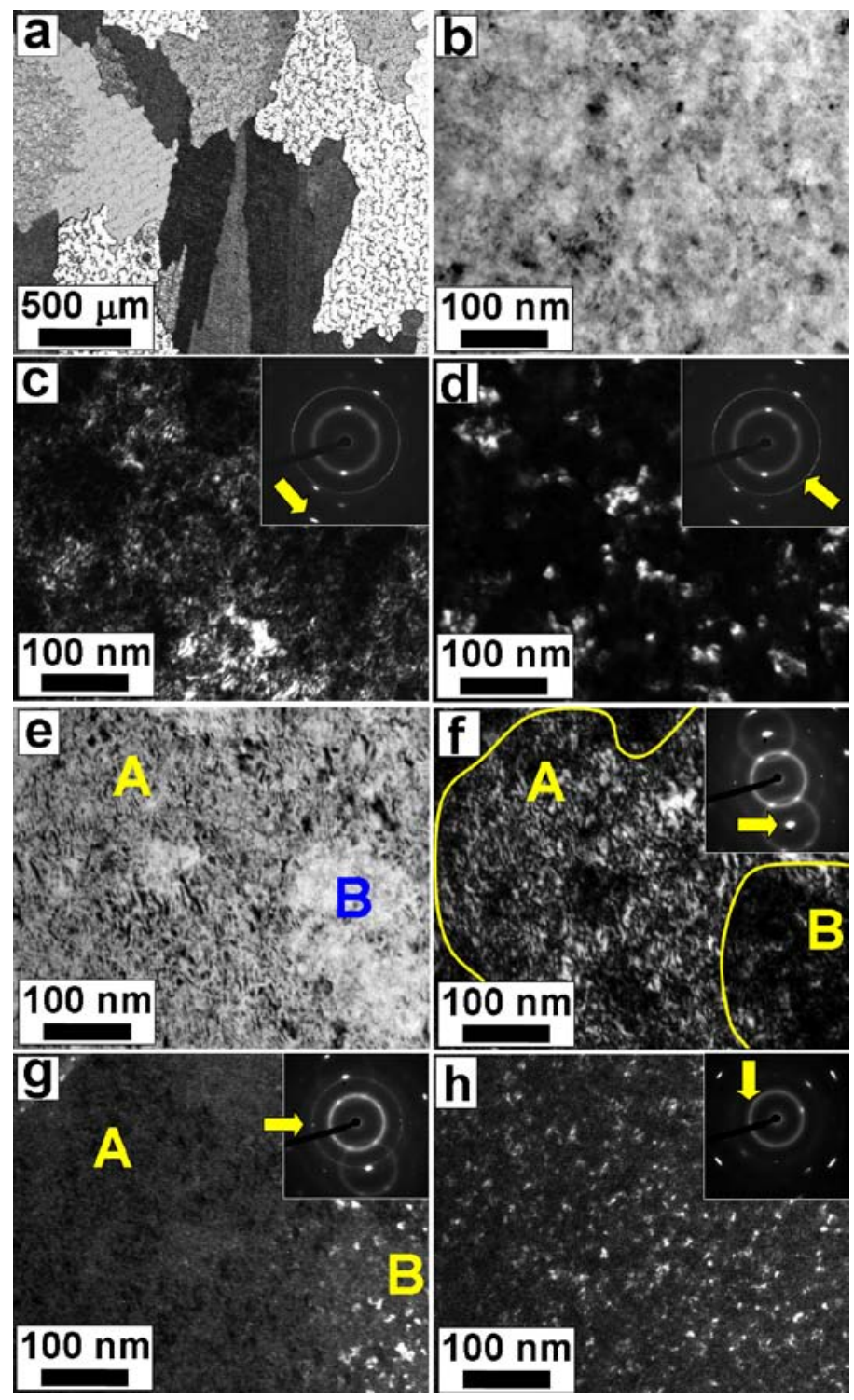

Fig. 4 (a) OM micrograph for annealed sample, and TEM micrographs and SAED patterns taken from surface of discs processed by HPT for (b-d) 0.25 and (e-h) 10 turns, where micrographs (c) and (d) are dark-field images of (b), micrographs (f) and (g) are dark-field images of (e). (h) is dark-field image taken from mid-point of thickness after 10 turns. Dark-field images were taken with diffracted beams indicated by arrows in SAED patterns. 


\section{Conclusions}

TiFe processed by HPT absorbed and desorbed 1.7 wt.\% hydrogen at room temperature for several cycles without any activation process. A heterogeneous microstructure including nanograins, coarse-grains, amorphous-like phase and disordered phase is observed after processing by HPT with a steady-state hardness of w1050 Hv.

\section{Acknowledgments}

One of the authors (KE) thanks the Japan Society for Promotion of Science (JSPS) for a postdoctoral scholarship for "Development of Hydrogen Storage Alloys Using Giant Straining Process”. This work was supported in part by WPI-I2CNER, in part by the Light Metals Educational Foundation of Japan, in part by a Grant-in-Aid for Scientific Research from the MEXT, Japan, in Innovative Areas "Bulk Nanostructured Metals" and in part by Kyushu University Interdisciplinary Programs in Education and Projects in Research Development (P\&P).

\section{REFEERENCES}

[1] Reilly JJ, Wiswall RH. Formation and properties of iron titanium hydride. Inorg Chem 1974;13:218-22.

[2] Kulshresshtha SK, Jayakumar OD, Bhatt KB. Hydriding characteristics of palladium and platinum alloyed FeTi. J Mater Sci 1993;28:4229-33.

[3] Inui H, Yamamoto T, Hirota M, Yamaguchi M. Lattice defects introduced during hydrogen absorption-desorption cycles and their effects on P-C characteristics in some intermetallic compounds. J Alloys Compd 2002;330-332:117-24.

[4] Lee JY, Park CN, Pyun SM. The activation process and hydriding kinetics of FeTi. J Less-Common Met 1983;89:163-8.

[5] Schlapbach L, Riesterer T. The activation of FeTi for hydrogen absorption. Appl Phys A 1983;32:169-82.

[6] Schlapbach L, Seiller A, Stucki Y. Surface segregation in FeTi and its catalytic effect on the hydrogenation II: AES and XPS studies. Mater Res Bull 1978;13:1031-7.

[7] Schober T, Wastlake DG. The activation of FeTi for hydrogen storage: a different view. Scripta Metall 1981;15:913-8.

[8] Mizuno T, Morozumi T. Titanium concentration in $\operatorname{FeTi}_{\mathrm{x}}(1<\mathrm{x}<2)$ alloys and its effect on hydrogen storage properties. J Less-Common Met 1982;84:237-44.

[9] Chung HS, Lee JY. Hydriding and dehydriding reaction rate of FeTi intermetallic compound. Int J Hydrogen Energy 1985;10:537-42.

[10] Bratanich TI, Solonin SM, Skorokhod VV. Mechanical activation of hydrogen sorption with intermetallic compounds $\mathrm{LaNi}_{5}$ and $\mathrm{TiFe}$ in powder systems. Int $\mathrm{J}$ Hydrogen Energy 1995;20:353-5.

[11] Zuchner H, Kirch G. Auger electron spectroscopy investigation of the activation of TiFe for hydrogen uptake. J Less-Common Met 1984;99:143-50.

[12] Trudeau ML, Dignard-Bailey L, Schulz R, Tessier P, Zaluski L, Ryan DH, et al. The 
oxidation of nanocrystalline FeTi hydrogen storage compounds. Nanostruct Mater 1992;1:457-64.

[13] Haraki T, Oishi K, Uchida H, Miyamoto Y, Abe M, Kokaji T, et al. Properties of hydrogen absorption by nano-structured FeTi alloys. Int J Mater Res 2008;99:507-12.

[14] Valiev RZ, Islamgaliev RK, Alexandrov IV. Bulk nanostructured materials from severe plastic deformation. Prog Mater Sci 2000;45:103-89.

[15] Valiev RZ, Estrin Y, Horita Z, Langdon TG, Zehetbauer MJ, Zhu YT. Producing bulk ultrafine-grained materials by severe plastic deformation. JOM 2006;58(4):33-9.

[16] Skripnyuk VM, Rabkin E, Estrin Y, Lapovok R. The effect of ball milling and equal channel angular pressing on the hydrogen absorption/desorption properties of Mg-4.95 wt\% Zn-0.71 wt\% Zr (ZK60) alloy. Acta Mater 2004;52:405-14.

[17] Zehetbauer M, Grossinger R, Krenn H, Krystian M, Pippan R, Rogl P, et al. Bulk nanostructured functional materials by severe plastic deformation. Adv Eng Mater 2010;12:692-700.

[18] Kusadome Y, Ikeda K, Nakamori Y, Orimo S, Horita Z. Hydrogen storage capability of $\mathrm{MgNi}_{2}$ processed by high pressure torsion. Scripta Mater 2007;57:751-3.

[19] Leiva DR, Jorge AM, Ishikawa TT, Huot J, Fruchart D, Miraglia S, et al. Nanoscale grain refinement and $\mathrm{H}$-sorption properties of $\mathrm{MgH} 2$ processed by high-pressure torsion and other mechanical routes. Adv Eng Mater 2010;12:786-92.

[20] Edalati K, Yamamoto A, Horita Z, Ishihara T. High-pressure torsion of pure magnesium: evolution of mechanical properties, microstructures and hydrogen storage capacity with equivalent strain. Scripta Mater 2011;64:880-3.

[21] Revesz A, Kis-Toth A, Varoa LK, Schafler E, Bakonyi I, Spassov T. Hydrogen storage of melt-spun amorphous $\mathrm{Mg}_{65} \mathrm{Ni}_{20} \mathrm{Cu}_{5} \mathrm{Y}_{10}$ alloy deformed by high-pressure torsion. Int $\mathrm{J}$ Hydrogen Energy 2012;37:5769-76.

[22] Lang J, Huot J. A new approach to the processing of metal hydrides. J Alloys Compd 2011;509:L18-22.

[23] Krystian M, Zehetbauer MJ, Kropik H, Mingler B, Krexner G. Effect of cold rolling on hydrogen sorption properties of die-cast and as-cast magnesium alloys. J Alloys Compd 2011;509S:S449-55.

[24] Revesz A, Kanya Z, Verebelyi T, Szabo PJ, Zhilyaev AP, Spassov T. The effect of high-pressure torsion on the microstructure and hydrogen absorption kinetics of ball-milled $\mathrm{Mg}_{70} \mathrm{Ni}_{30}$. J Alloys Compd 2010;504:83-8.

[25] Danaie M, Mauer C, Mitlin D, Huot J. Hydrogen storage in bulk Mg-Ti and Mgestainless steel multilayer composites synthesized via accumulative roll-bonding (ARB). Int J Hydrogen Energy 2011;36:3022-36.

[26] Skripnyuk VM, Rabkin E, Bendersky LA, Magrez A, Carreno-Morelli E, Estrin Y. Hydrogen storage properties of as-synthesized and severely deformed magnesium-multiwall carbon nanotubes composite. Int J Hydrogen Energy 2010;35:5471-8.

[27] Lima GF, Jorge Jr AM, Leiva DR, Kiminami CS, Bolfarini C, Botta WJ. Severe plastic 
deformation of Mg-Fe powders to produce bulk hydrides. J Phys Conf Ser 2009;144:012015.

[28] Edalati K, Horita Z, Mine Y. High-pressure torsion of hafnium. Mater Sci Eng A 2010;527:2136-41.

[29] Gubicza J, Chinh NQ, Labar JL, Dobatkin S, Hegedus Z, Langdon TG. Correlation between microstructure and mechanical properties of severely deformed metals. J Alloys Compd 2009;483:271-4.

[30] Yoon EY, Lee DJ, Kim TS, Chae HJ, Jenei P, Gubicza J, et al. Microstructures and mechanical properties of Mg-Zn-Y alloy consolidated from gas-atomized powders using high-pressure torsion. J Mater Sci 2012;47:7117-23.

[31] Sun PL, Zhao YH, Cooley JC, Kassner ME, Horita Z, Langdon TG, et al. Effect of stacking fault energy on strength and ductility of nanostructured alloys: an evaluation with minimum solution hardening. Mater Sci Eng A 2009;525:83-6.

[32] Figueiredo RB, Kawasaki M, Langdon TG. An evaluation of homogeneity and heterogeneity in metals processed by high-pressure torsion. Acta Phys Pol A 2012;122:425-9.

[33] Cao Y, Wang YB, Figueiredo RB, Chang L, Liao XZ, Kawasaki M, et al. Three-dimensional shear strain patterns induced by high-pressure torsion and their impact on hardness evolution. Acta Mater 2011;59:3903-14.

[34] Valiev RZ, Sabirov I, Zhilyaev AP, Langdon TG. Bulk nanostructured metals for innovative applications. JOM 2012;64(10):1134-42.

[35] Ciuca O, Tsuchiya K, Yokoyama Y, Todaka Y, Umemoto M. Effect of nanocrystallization and twinning on hardness in $\mathrm{Ni}_{3} \mathrm{Al}$ deformed by high-pressure torsion. Mater Trans 2010;51:14-22.

[36] Huang JY, Zhu YT, Liao XZ, Valiev RZ. Amorphization of TiNi induced by high-pressure torsion. Phil Mag Lett 2004;84:183-90.

[37] Geist D, Rentenberger C, Karnthaler HP. Extreme structural inhomogeneities in high-pressure torsion samples along the axial direction. Acta Mater 2011;59:4578-86.

[38] Rentenberger C, Mangler C, Scheriau SG, Pippan R, Karnthaler HP. TEM study of local disordering: a structural phase change induced by high-pressure torsion. Mater Sci Forum 2008;584-586:422-7.

[39] Edalati K, Toh S, Watanabe M, Horita Z. In situ production of bulk intermetallic-based nanocomposites and nanostructured intermetallics by high-pressure torsion. Scripta Mater 2012;66:386-9.

[40] Edalati K, Toh S, Iwaoka H, Watanabe M, Horita Z, Kashioka D, et al. Ultrahigh strength and high plasticity in TiAl intermetallics with bimodal grain structure and nanotwins. Scripta Mater 2012;67:814-7.

[41] Zhilyaev AP, Langdon TG. Using high-pressure torsion for metal processing: fundamentals and applications. Prog Mater Sci 2008;53:893-979.

[42] Chen YJ, Li YJ, Walmsley JC, Gao N, Roven HJ, Starnik MJ, et al. Microstructural heterogeneity in hexagonal close-packed pure Ti processed by high-pressure torsion. J Mater Sci 2012;47:4838-44. 
[43] Fujita T, Horita Z, Langdon TG. Characteristics of diffusion in Al-Mg alloys with ultrafine grain sizes. Phil Mag A 2002;82:2249-62.

[44] Divinski SV, Reglitz G, Rosner H, Estrin Y, Wilde G. Ultra-fast diffusion channels in pure Ni severely deformed by equal-channel angular pressing. Acta Mater 2011;59:1974-85.

[45] Oberdorfer B, Lorenzoni B, Unger K, Sprengel W, Zehetbauer MJ, Pippan R, et al. Absolute concentration of free volume-type defects in ultrafine-grained Fe prepared by high-pressure torsion. Scripta Mater 2010;63:452-5. 